general knowledge as possible, as he might thereby often be able to engender confidence in his patient. He should also endeavour to "see himself as others see him," so as to be better able to deal with them. Much help in this direction might be obtained from a study of works of fiction, in which medical men are portrayed from the outside. The profession was often misunderstood and misjudged by the public, but this should never be allowed to discourage its members from the prosecution of their task. Nor should they be disheartened by the inexactitude of the science on which their art was founded, and the large proportion of guesswork which there necessarily was in their methods. "If," concluded the President, " our work, like that of the student in every branch of science, is largely a work of conjecture, it is no fault of ours that our strivings have such a limitation. We have only to see to it that our conjectures are framed aright; that we toil after the attainment of what is noble, enduring, and true, recognising in our quest that there must be always things beyond knowledge, and moved by a faith in the sublimity of natural law, which we may not express in finite terms, but which may inspire us with resolution to go forward and with a saving humility as we gaze meanwhile upon the

$$
\begin{aligned}
& \text { Temples that crowd the crumbled brink } \\
& \text { O'er hanging Truth's eternal flow, } \\
& \text { Their tablets bold with " what we think," } \\
& \text { Their echoes dumb to " what we know." }
\end{aligned}
$$

\section{ON MASSAGE.}

Delireved at the Annual Meeting of the West Somerset Branch. BY ABRAHAM COLLES, M.D.,

President of the Branch.

AFTER acknowledging the honour conferred on him by the Branch in choosing him for its President, Dr. Colles went on to say that, Mr. W.J. Penny's paper on “Bone-setting" (JourNA L, vol. i, 1888, p. 1102) had suggested to him the desirability of dealing in a similar spirit with a cognate subject, namely, massage, a system of treatment under which a fresh body of charlatans seemed inclined to take refuge. He had had several opportunities of observing the results in patients of his own, and others who had undergone the treatment. Judging from advertisements in the medical journals there were "experienced masseurs" or masseuses who were willing to undertake the cure of anything or anybody. So far as he could learn, the greater number of such advertisers had no qualification whatever entitling them to the high-sounding titles they assumed. They were simply persons who would rub or knead you-for a consideration-but who knew nothing about massage proper. It had been truly said, “There is as much difference between Metzger's massage and the so-called English massage, as there is between champagne and gooseberry. The difficulty is that the majority of people do not know one from the other, and most patients are perfectly satisfied as long as the rubber gives them a full hour, works hard, and gets hot and a little 'dewy.' The isolation of individual muscles or groups of muscles is at a discount, whilst motor points are almost unknown quantities." It need hardly be said that the effects of this spurious massage are often disappointing, and thus a system capable of producing great results when properly used was in danger of falling into undeserved disrepute. Quack massage flourished in consequence of the gullibility of the public; rubbing and kneading were useful in fit cases and (just as with the bone-setters) the successful cases made a noise, while the failures were discounted. The medical profession was not free from blame in this matter, much of the success of these quacks being due to the apathy of orthodox practitioners on the subject.

It was often sairl that massage was no new thing, but was practised by the Greeks and Romans and other nations of antiquity. The practice of the ancients, however, resembled that of modern " rubbers," but was not massage ; it was almost identical with the shampooing still used in the East after the bath. Massage proper embraced a variety of manipulations suitable to different conditions. The simplest form (effeurage), consisting in a stroking movement made with the hand in a centripetal direction. If an entire limb was to be influenced it was grasped firmly at the point at which the movement was to begin, and the hand then passed firmly towards the body as far as might be required the other hand beginning a movement just as the first ended, and so each hand taking it up alternately. If it was to be applied to a muscle or group of muscles it was important to follow as cloeely as possible the direction of muscle-fibres. For deep-seated tissues the knuckles might be substituted for the palm of the hand. The amount of pressure exercised and the rapidity of the movement must depend on individual circumstances. This form of massage was often useful in reducing passive enlargements, either solid or fluid. The result was obviously due to an increase of the circulation, both venous and lymphatic. Another form of massage was pétrissage, which consisted in picking up a portion of muscle, or other tissue, with both hands, and subjecting it to firm pressure, rolling it at the same time between the fingers and the underlying tissues. The movement was made from below upwards, and the parts were squeezed in much the same way as one would squeeze out the contents of a sausage. It was of importance to proceed uniformly, and not to jump from spot to spot, and it was essential to bear in mind the arrangement of the groups of surface muscles and to keep well in the interstices. In a case of infantile paralysis affecting the lower extremities only, he had seen effleurage and petrissage used in combination, with the result that first warmth, then responsiveness to galvanism, and, finally, voluntary movement were restored. He had more than once seen benefit produced by massage in cases of chronic constipation, petrissage being applied to the abdominal muscles, and a combination of that movement and efferurage along the ascending transverse and descending colon. The action here was probably throefold-(1) increase of intestinal secretion, (2) stimulation of peristaltic action, (3) mechanical movemunt of accumulated fæces. He had also seen rheumatism of individual muscles yield to massage when medicines, liniments, medicinal baths, and galvanism had done so little good that almost total loss of movement had resulted, with very considerable suffering. In one case careful pétrissage for a few weeks caused almost total disappearance of the symptoms.

In certain surgical cases a combination of effleurage with "friction" was often useful. The term "friction" was not very appropriate, as would be seen from the following description of the movement referred to. "The finger-tips of one hand held at right angles to the axis of the limb rub across and across in narrow ellipses, while the fingers of the other hand stroke parallel to the axis of the limb." Massage should not be used when acute inflammation was present, except in cases of sprain. If massage it friction were begun immediately after the accident discoloration and swelling rapidly disappeared. This manipulation continued for a quarter of an hour and repeated at intervals of a few hours. would in most cases do away with evrporating lotions, etc., and with the necessity of confinement to bed for some weeks. In the cases most liable to passinto the hands of bone-setters, namely, those in which joints have become stiffened as the result of chronic inflammation or severe sprains, massage was often extremely serviceable, and obviated all need for the violent measures so freely used by bone-setters. He had had no personal experience of the effect of massage on the union of fractures, but it was said by competent authorities to be eminently satisfactory, hastening repair, and shortened the period of treatment to a wonderful extent.

There were many other forms and applications of massage, which he knew only by report, for example, digital pressure on nerve points for the relief of pain and tapotement. The latter might be described as a regulated system of percussion; it was administered by the front of the finger-tips, by the back of the hand, by the edge of the hand, or with the palm, so as to contain a cushion of air. In addition to these, special instruments of percussion were at times employed. A case was cited in which a primitive form of this method was resorted to by the patient himself about a century ago ; by this means he was said to have cured himself of rheumatism, a tendency to gout, tic douloureur, cramp, and other diseases, including a cataract. It appeared to him (Dr. Colles) that every medical practitioner was now bound to make himself as well acquainted with the scientific use of massage as with other branches of practice. He thought there was a great field here for experiment and research. As yet not much had been done in this country to reclaim massage from the hands of ignorant pretenders. The Weir-Mitchell system, which was somewhat allied to it, though different in scope and in application, was now pretty well established in London, and undoubtedly produced good results at times. It was, however, inconvenient and expensive, and not by any means uniformly successful. This method was not massage, though often confused with it, and it could never take the place which massage ought to hold.

Massage could never come into general use so long as its exer- 
cise depended solely on the medical man. He must have the assistance of skilled manipulators, who would faithfully carry out his directions in his absence, just as a good nurse did in her own province. Some efforttras now being mäde in London to supply this want, but there was no reason why the Taunton and Somerset Hospital should not now furnish practitioners in 'West' Somerset with what was required in that line. It was said that two years of training were needed to make a nurse competent in massage; if it was remembered that a considerable knowledge of anatomy was indispensable, this estimate would not seem exaggerated. Massage was of course a panacea, but the list of maladies in which competent authorities had found it useful numbered forty or fifty. The physiological effects of massage were not yet fully worked out, but it appeared that effleurage stimulated the skin muscles, produced dilatation of the superficial vessels, and insensible perspiration, excited the skin reflexes, and, acting through the skin nerves, increased the rapidity of the heart's action, as well as of the circulation: Pétrissage forced the lymph out of the muscles, increased the velocity of the blood current in the part; temporarily decreased the size of a limb, and increased its muscular power. Unlike effleurage, it reduced instead of increasing the pulse rate, more especialky. when it was applied to the abdomen. The local effects of massage à friction were much the same as those of petrisságe, while 'tapotement was most effectual in exciting muscular contraction: The electrical excitability of muscle was also increased under massage, as was seen in the restoration of that power in cases of paralysis, in which it had been previously dormant. Medical gymnastics and calisthenics might often be advantageously combined with massage.

\section{A SHORT RETROSPECT OF MEDICAL PROGRESS.}

Delivered at the Annual Meeting of the North Wales Branch.

$$
\text { B y E. J. L L O Y D, M.D.Aberd., }
$$

AFTER returning thanks for the honour done him in electing him President, Dr. Lloyd said he proposed to speak of some of the most prominent advances which medicine and surgery had made in recent years, and also to call attention to a few of the most pressing topics of medical politics. One of the signs of the present time was the energy which was being expended in the pursuit of germs. By the discovery of the tubercle bacillus, Koch threw open a new continent to scientific research, and the results obtained so far by the various explorers had yielded a rich produce of knowledge. A new science had sprung into existence within the last two or three years-namely, bacteriology ; professorial chairs of bacteriology were being founded at the centres of medical instruction, and in the laboratories attached thereto germs were being cultivated and isolated with a success which augured well for valuable discoveries in the future. No reference to this subject would be complete which did not include the name of Louis Pasteur. It was not necessary here to recapitulate any of his triumphant discoveries, or to remind them what he had so far achieved in his efforts to combat the virulence of rabies. The scientific world would watch with interest his proposal to deal with the rabbit scourge in Australia by means of the cholera microbe, if the consent of the colonists to this suggestion could be obtained. Perhaps the latest development in the science of bacteriology was the alleged discovery of a cancer microbe, but all was yet uncertain with regard to it. There might or might not be a cancer microbe, but.we did well to hope that there was; for in this direction alone did it seem possible that any gleam of light could come in the advance of our knowledge of the disease. The gradual elaboration of our knowledge of germ life had not solely been found of use in the discovery of the cause of disease, but also in the antiseptic treatment of wounds. A most important detail had recently come to light upon the subject of antiseptics -namely, that of the truly antiseptic power of soaps and alkalies. Experimentation had demonstrated that instruments which had been previously washed with soap and potash were much more quickly and effectually sterilised by carbolic and sublimate solutions than by the latter two reagents alone. The President then dwelt at some length on the virtues of iodoform and perehloride of mercury as germicides, and on the conditions under which they should be used. He then referred to the rapid progress which had been made within the past few years in the surgery of the brain.
Two factors had contributed to this gratifying result-namely; the confidence which antisepticisid gate to suirgeons in the well-doing of their operation wounds, and advances in physiology, by which surgeons were able to localise the precise position of lesions. Abdominal surgery, again, had made immense progress during recent years. Surgeons nowadays thought no more of opening the abdomen than surgeons in old days would have thought of opening an abscess. This confidence came from the knowledge which extended experience had taught us of how to treat the peritoneum. It was now known that the peritoneum was tolerant of almost any amount of surgical interference, provided it was treated with, so to speak, surgical politeness. Lapa= rotomy was now performed for many and variotis conditiots of injury and disease of the abdomen. Attention might first bs directed to the good results which had been obtained by its performance in those cases of acute intestinal obstruction, 95 per cent. of which, if unrelieved by art, proved fatal. In a collected series of sixty-nine cases of this description, the mortality was 46 per cent., and even many of them were in a condition of profound collapse at the time of operation. Under more favourable condi. tions in the future, we might hope for a better record than that. Laparotomy had also been performet during the past year in a great number of instances of wounds of the intestines, and in cases of rupture of the urinary bladder, with resiltts which, on the whole; were satisfactory. It had even been done in cases of perfordtion of the intestine occurring during typhoid fever, but without success. The radical cure of hernia was tlso now a successful procedure. Leaving the field of abdominal surgery, intubation of the larynx had been proposed by Dr. O'Dwyer, as a substitute for tracheotomy, and the operation seemed worthy of trial. The application of electricity to the treatment of disease had also undergone great development in recent years. Just as electricity was now competing with gas in the commersial world, so might it be said that it had entered into competition with the knife in the treatment of many forms of disease. Electricity, as applied to medicine, might now be spoken of as an exact science; and it was impossible to doubt that it was destined to occupy in the future a valuable position as a curative agent. Electrolysis had been found of great service in strictures of the urethra and the rectuin. With regard to Dr. Apostoli's treatment of uterine fibroids by electrolysis, great claims were advanced in its behalf, but the method had so far not found much favour amongst experts in this country. The treatment of these cases by electrolysis, however, had not yet had a fair trial in England, and until this had been the case, it was only right to suspend judgment. In adverting to this subject, one was only more deeply impressed with the extent to which electricity was competing with the knife in the treatment of disease; for here was an instance in which the knife would be altogether superseded, if the results of the application of the current should prove, after extended trial in the hands of independent observers, to be in the end satisfactory. Passing then to medical politics, the President said the subject was, in the present day, becoming more and more one which demanded the attention of every practitioner who had the interest of his profession at heart. Medical men, as a rule, were credited with possessing very little business capacity. "Common experience (he continued) shows that much seems to be done for us in the passing of laws without any consultation of the profession at large. The fact that this is so is, after all, perhaps, our own fault. We are too lethargic in the matter of striving for and protecting our own interests. Medical men would apparently, by their action, make the outside. world believe that they were too much engrossed in their daily work to undertake and organise agitations in the protection of their rights and in the correction of manifest imperfections in the laws which affect them. But, judging from the signs of the times, it does not seem to be probable that this will always prove to be the case. There are hopeful indications that we are gradually acquiring the habit of bestirring ourselves when necessary in the cause of our rights and interests. The wellconceived efforts which have recently been made to repel the autocracy of the government of the Royal College of Surgeons of England is an earnest of the growing interest which is being taken in the furtherance of many much needed reforms. Every member of the profession has a voice in the matters which affect his interests, if he only will trouble himself to use it, and it is plainly dur duty collectively to make our voices heard when the occasions arise which demand our serious attention. In the furtherance of this view I think that the Branches of this great Associátion should devote certain of their meetings in the year to 